\title{
Boost DC/DC Converter Nonlinearity and RHP-Zero: Survey of the Control-to-Output Transfer Function Linearization Methods
}

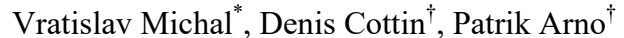 \\ ${ }^{*}$ STMicroelectronics, 12 rue Jules Horowitz, 38000 Grenoble - France \\ *Infineon Technologies Austria AG, Siemensstraße 2, 95000 Villach - Austria \\ vratislav.michal@infineon.com
}

\begin{abstract}
This invited paper is dedicated to both the nonlinear behavior of a step-up DC/DC converter, and to its linearization. It explains the nonlinear DC and AC control-to-output transfer function and its RHP-zero. The explanation is based on linearized models developed in the paper. These models are suitable for SPICE-like environment, and allow to obtain accurate symbolic equations in Matlab format. The linearization methods based on tri-state PWM and predistortion are also described. The description is followed by a Matlab algorithm allowing fast computation of the voltagemode PID controller for pre-distorted PWM modulator. As a result, a linearized converter operating in wide duty-cycle range is designed with voltage mode feedback loop.
\end{abstract}

\section{INTRODUCTION: IDEAL CHARACTERISTICS}

A boost converter is a non-isolated power converter that may be used when a higher output voltage than the one provided by the input source is required. It contains two power switches, one inductor and an output capacitor. Boost converter, including dominant parasitic resistances, is shown in Fig. 1.

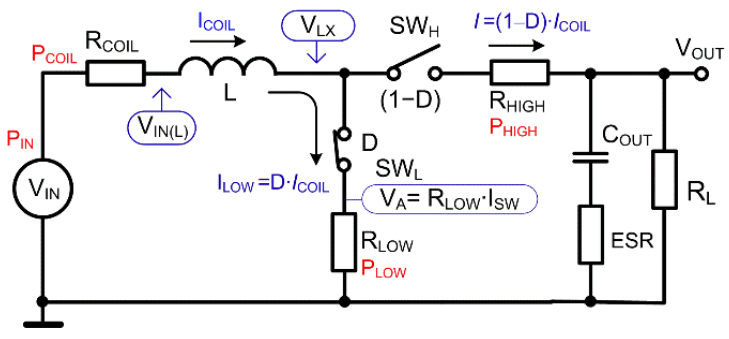

Fig. 1. Basic topology of the boost DC-DC converter.

The converter operates in two phases: phase $D$, where $\mathrm{SW}_{\mathrm{L}}$ is closed during D-portion of the clock period and the inductor current increase, and $(1-D)$ phase where the inductor energy is released to the load via the high-side switch $\mathrm{SW}_{\mathrm{H}}$. For an ideal converter ( $R_{\mathrm{COIL}}, R_{\mathrm{LOW}}$, and $\left.R_{\mathrm{HIGH}}=0\right)$, the output voltage can be determined by the volt-second balance as a function of the input voltage $V_{\mathrm{IN}}$ and duty-cycle $D[1]$ :

$$
V_{\text {oUT }}=\frac{V_{I N}}{1-D}
$$

The inductor (input) current is given by dividing the load current by high-side switch conduction time:

$$
I_{\text {COIL }}=\frac{I_{\text {OUT }}}{1-D}=\frac{V_{I N}}{R_{L}(1-D)^{2}}
$$

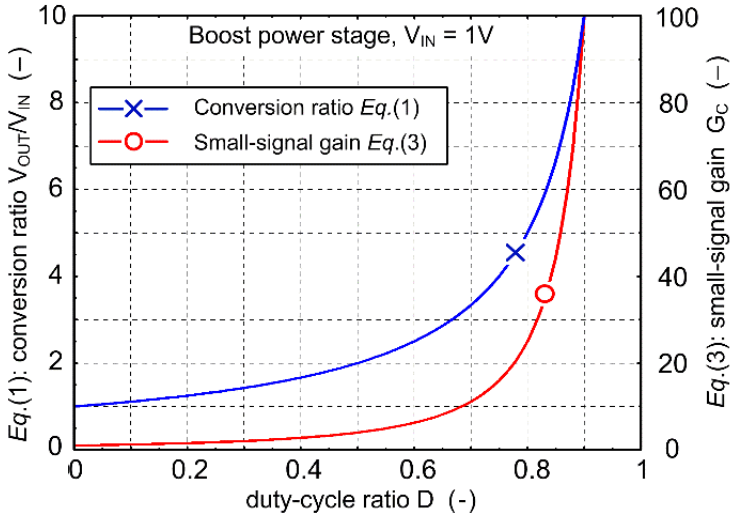

Fig. 2. Conversion ratio and small-signal gain $G_{\mathrm{C}}$ of the ideal boost converter [14].

Although these basic characteristics of the boost converter are well known, its modeling can be complicated due to the strong nonlinear behavior. This concerns namely the nonlinearity of DC transfer function (1), and the nonlinear dynamic response with the well-known right-half plane (RHP) zero. Unlike the (fairly linear) buck converter, boost converter belongs to a class of nonlinear and time-variant systems. Consequently, its transient response depends on the steady-state operating point [2], [3].

\section{A. Static Control Gain $G_{C}$}

Most significant non-linearity of the boost converter is the static control-to-output transfer function (1), and its static (DC) gain $G_{\mathrm{C}}$. This gain directly impacts the stability of the feedback control loop. It can be obtained by derivation of (1):

$$
G_{C}=\frac{\partial V_{O U T}}{\partial D}=\frac{V_{I N}}{(1-D)^{2}}
$$

The control gain $G_{\mathrm{C}}$ is shown together with the output voltage (1) as a function of the duty-cycle in Fig. 2. Here, high variation (up to $30 \mathrm{~dB}$ ) of $G_{\mathrm{C}}$ with dutycycle can be seen.

\section{B. Nonlinear Dynamic (transient) Response}

The dynamic response is governed by the operating point given by $V_{\mathrm{IN}}, V_{\mathrm{OUT}}, I_{\mathrm{OUT}}$ and $D$. As an example, the Bode-plot of the control-to-output transfer function for three values of $D$ is shown in Fig. 3 . Here, each duty-cycle exhibits a different frequency characteristic, and thus a different transient response. 


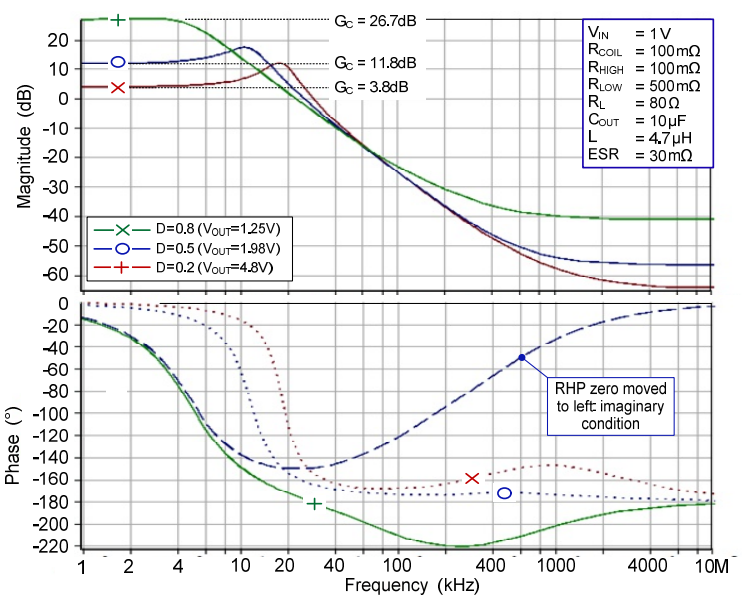

Fig. 3. Control-to-output transfer functions $G_{\mathrm{C}(\mathrm{s})}$ for three values of the duty-cycle $D$.

This paper is organized as follows: averaged switches model allowing to obtain mathematical description of both $\mathrm{DC}$ and $\mathrm{AC}$ transfer function is presented in section II. Explanation of the RHP zero is provided in section III. Methods for the transfer function linearization based on the tri-state PWM and predistortion PWM generator are described in sections $I V, V$, and $V I$, whereas synthesis of the voltage-mode feedback control loop is presented in section VII.

\section{LINEAR DC AND AC MODEL OF THE BOOST CONVERTER}

The switching between low and high side switch results in a periodical switching between two subcircuits of the boost converter. Consequently, direct $\mathrm{DC}$ and $\mathrm{AC}$ analysis cannot be used.

For frequencies below $f_{\mathrm{SW}}, \mathrm{AC}$ and DC modeling can be performed using averaging techniques. The averaging aims to replace the pulsating currents and voltages of the switches by their respective averaged values (averaged within one conduction cycle). In particular, state-space averaging SSA [4],[5], and modeling by averaged switches [6],[7],[8] are frequently used. Circuit's parameters obtained by averaging are usually referred as periodic steady-state values, and are labeled by $\langle-\rangle$ bracelets.

This section provides an "user friendly" model with averaged switches. This model includes all the parasitic resistances shown in Fig. 1. Additionally, accurate symbolic DC and AC transfer functions are also generated. This facilitates both electrical simulation and accurate symbolic manipulation with (e.g.) Matlab or Simulink.

The modeling with averaged switches is based on the substitution of $\mathrm{SW}_{\mathrm{L}}$ and $\mathrm{SW}_{\mathrm{H}}$ by a couple of linear voltage and current controlled sources VCVS and CCCS [7],[8]. Generally, available models [6],[7],[8] consider only the inductor parasitic resistance $R_{\mathrm{COIL}}$. However, resistances $R_{\mathrm{LOW}}$ and $R_{\mathrm{HIGH}}$ can significantly influence the parameters of the model. On this account, these resistances have been included in the averaged model Fig. 4 developed in the following.

Main advantage of this technique is the possibility to directly use accurate SPICE models of the semiconductors switches (MOSFET or diodes) in the linearized model. As demonstrated in Biolek 2008 [11] (on an example of the boost converter model), the accuracy of the simulation is greatly improved.

\section{A. Switch Averaging Model of a Boost Converter}

While the low-side switch $\mathrm{SW}_{\mathrm{L}}$ is $\mathrm{ON}$ during $D$ portion of the switching period $T_{\mathrm{SW}}$, its average current is $\left\langle i_{\mathrm{SW}(\mathrm{L})}\right\rangle=D \cdot I_{\mathrm{COIL}}$ [1]. As shown in Fig. 4, current $\left\langle i_{\mathrm{SW}(\mathrm{L})}\right\rangle$ is then realized by CCCS with current gain $D$.

The VCVS output $\left\langle v_{\mathrm{B}}\right\rangle$ is defined by the volt-second balance. In periodic steady-state, the volt-second balance corresponds to a zero average voltage across the ideal inductor during [9]:

$$
\left\langle v_{L}\right\rangle=\int_{0}^{T_{S W}} v_{L}(t) d t=0
$$

This rule can be used to obtain the DC transfer function of the boost converter from Fig. 1 as follows: during the low-side conduction phase $D$, inductor voltage is $V_{\mathrm{IN}(\mathrm{L})}-V_{\mathrm{A}}$, where $V_{\mathrm{A}}=I_{\mathrm{COIL}} R_{\mathrm{LOw}}$. Similarly, inductor voltage during the high-side switch conduction phase $(1-D)$ is $V_{\mathrm{IN}(\mathrm{L})}-\left(V_{\mathrm{OUT}}+V_{\mathrm{RHIGH}}\right)$. Here, $V_{\mathrm{RHIGH}}=R_{\mathrm{HIGH}} \cdot I_{\mathrm{COIL}}$. The volt-second balance can be then written as:

$$
\left(V_{I N(L)}-V_{A}\right) \cdot D+\left(V_{I N(L)}-\left(V_{\text {OUT }}+V_{R H I G H}\right)\right)(1-D)=0
$$

In order to satisfy this condition by linearized model, a voltage controlled voltage source $v_{\mathrm{B}}$ is added between the inductor and $R_{\mathrm{HIGH}}$.

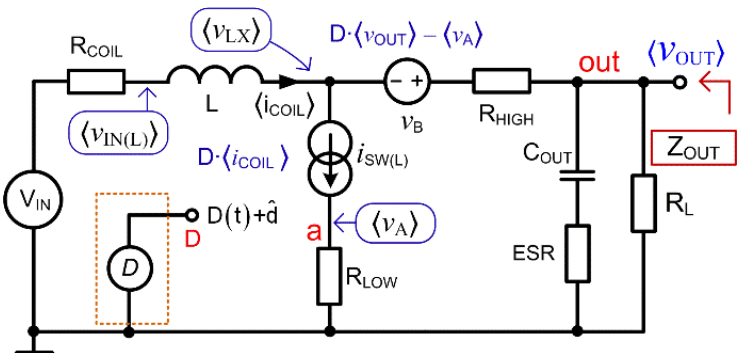

Fig. 4. Nonlinear averaged-switch model of converter from Fig. 1 . Controlled sources $v_{\mathrm{B}}$ and $i_{\mathrm{SW}(\mathrm{L})}$ are defined as follows: $v_{\mathrm{B}}=$ $\mathrm{v}(\mathrm{D}) * \mathrm{v}($ out $)-\mathrm{v}(\mathrm{a})$, and $i_{\mathrm{s} w(\mathrm{~L})}=\mathrm{i}(\mathrm{L})^{*} \mathrm{v}(\mathrm{D})$. Term relating to the ESR in $v_{\mathrm{B}}$ as described in [6] is neglected. This simplification assumes the use of a low-ESR (ceramic) output capacitor $C_{\text {OUT }}$.

Condition $\left\langle v_{\mathrm{L}}\right\rangle=0$ from (4) allows to assume $\left\langle v_{\mathrm{IN}(\mathrm{L})}\right\rangle=\left\langle v_{\mathrm{LX}}\right\rangle$. Average output voltage can be then written as:

$$
\left\langle v_{\text {OUT }}\right\rangle=\left\langle v_{I N(L)}\right\rangle+\left\langle v_{B}\right\rangle-\left\langle v_{R H I G H}\right\rangle
$$

Since $\left\langle i_{\text {out }}\right\rangle=(1-\mathrm{D}) \cdot I_{\mathrm{COIL}}$, average voltage $\left\langle v_{\mathrm{RHIGH}}\right\rangle$ from (6) can be written as $\left\langle v_{\mathrm{RHIGH}}\right\rangle=(1-\mathrm{D}) \cdot V_{\mathrm{RHIGH}}$. Moreover, non-pulsating terms from (5) can be replaced by their average values: $V_{\mathrm{IN}(\mathrm{L})}=\left\langle v_{\mathrm{IN}(\mathrm{L})}\right\rangle$, and $V_{\text {OUT }}=\left\langle v_{\text {OUT }}\right\rangle$. Solving (5) for $\left\langle v_{\mathrm{IN}(\mathrm{L})}\right\rangle$, and applying it in (6) result in:

$$
\left\langle v_{B}\right\rangle=D \cdot\left\langle v_{\text {OUT }}\right\rangle-\left\langle v_{A}\right\rangle
$$

here $\left\langle v_{\mathrm{A}}\right\rangle=D \cdot V_{\mathrm{A}}$ is the voltage available in the circuit shown in Fig. 4. As already mentioned, $\left\langle v_{\mathrm{B}}\right\rangle$ and $\left\langle i_{\mathrm{SW}(\mathrm{L})}\right\rangle$ can be implemented by controlled sources VCVS and CCCS, available in SPICE environments. For simulations with variable duty-cycle (e.g. feedback loop transient, AC control-to-output transfer 
function), the controlled sources should enable insert an expressions $D \cdot I_{\text {COIL }}$ and (7), that refers to variable signal $D(t)$ or $\mathrm{AC}=1$. An example of comparison between switched-mode simulation and simulation with linearized model is shown in Fig. 6.

One limitation of the averaged model from Fig. 4 is the estimation of power efficiency $\eta$. The inaccuracy concerns the simulation of the power dissipated by resistances $R_{\mathrm{LOW}}$ and $R_{\mathrm{HIGH}}$. The RMS value of the PWM pulsating current with duty-cycle $D$ is given as $I_{R M S}=I_{P E A K} \sqrt{D} \quad[1]$. Related dissipated power is $R I_{P E A K}^{2} D$. While average current $\left\langle i_{A V G}\right\rangle=I_{P E A K} D$, the power measured on Fig. 4 model resistances $R_{\mathrm{LOW}}$ and $R_{\mathrm{HIGH}}$ is $R I_{P E A K}^{2} D^{2}$ and $R I_{P E A K}^{2}(1-D)^{2}$, respectively. As a result, the power dissipated on resistances $R_{\mathrm{LOW}}$ and $R_{\mathrm{HIGH}}$ must be divided by their respective conduction ratios, i.e. $P_{\mathrm{LOW}}=R_{\mathrm{LOW}} \cdot\left\langle i_{S W(L)}^{2}\right\rangle / D$, and $P_{\mathrm{HIGH}}=R_{\mathrm{HIGH}} \cdot\left\langle i_{S W(L)}^{2}\right\rangle /(1-D)$.

\section{B. DC Transfer Function}

Compared to ideal output voltage $V_{\text {OUT }}(1)$, real boost converter from Fig. 1 generates lower output voltage for the same duty-cycle. Output voltage for such real boost converter can be obtained by analysis of Fig. 4 model as:

$$
V_{\text {oUT }}=\frac{R_{L}(1-D) V_{I N}}{D^{2} R_{L}-D\left(2 R_{L}+R_{H I G H}-R_{L O W}\right)+R_{L}+R_{H I G H}+R_{\text {COIL }}}
$$

The decrease of $V_{\text {OUT }}$ is shown in Fig.5. The conversion characteristics contains three significant areas [10]:

1) $\boldsymbol{D}<\boldsymbol{D}_{\text {CRIT }}$ : normal (positive gain) operations. The $V_{\text {OUT }}$ is close to ideal value given by Eq.(1), (curve $R_{\mathrm{L}}=\infty$ ),

2) $\boldsymbol{D}=\boldsymbol{D}_{\text {CRIT }}$ : providing maximum output voltage $V_{\mathrm{MAX}}$ and maximal possible output power [10].

3) $\boldsymbol{D}>\boldsymbol{D}_{\text {CRIT: }}$ negative gain area, where the output voltage decreases when duty-cycle increases.

The value of critical duty cycle $D_{\text {CRIT }}$ can be obtained by setting the $1^{\text {st }}$ derivative $d\left(V_{\text {OUT }}\right) / d D=0$ as:

$$
D_{\text {CRIT }}=1-\sqrt{\left(R_{\text {COIL }}+R_{\text {LOW }}\right) / R_{L}}
$$

where $D_{\text {CRIT }}$ is independent on $R_{\mathrm{HIGH}}$ [10]. More accurate equations of inductor current (2) and output resistance (being ideally zero) can also be derived by the help of Fig. 4 model as:

$$
\begin{gathered}
I_{\text {COIL }}=\frac{V_{I N}}{D^{2} R_{L}-D\left(2 R_{L}+R_{H I G H}-R_{L O W}\right)+R_{L}+R_{H I G H}+R_{\text {COIL }}} \\
R_{\text {OUT }}=\frac{R_{\text {COIL }}+(1-D) R_{\text {HIGH }}+D R_{\text {LOW }}}{(1-D)^{2}}
\end{gathered}
$$

Both values increase with $D$. The $R_{\text {OUT }}$ given by (11) allows also to obtain an alternative expression (8) as:

$$
V_{\text {OUT }}=V_{\text {IN(IDEAL) }}-R_{\text {OUT }} \cdot I_{\text {OUT }}
$$

where $V_{\mathrm{IN}(\mathrm{IDEAL})}$ is given by (1). Improved control-tooutput static gain given previously by ideal Eq.(3) can be obtained by derivative of (8) as:

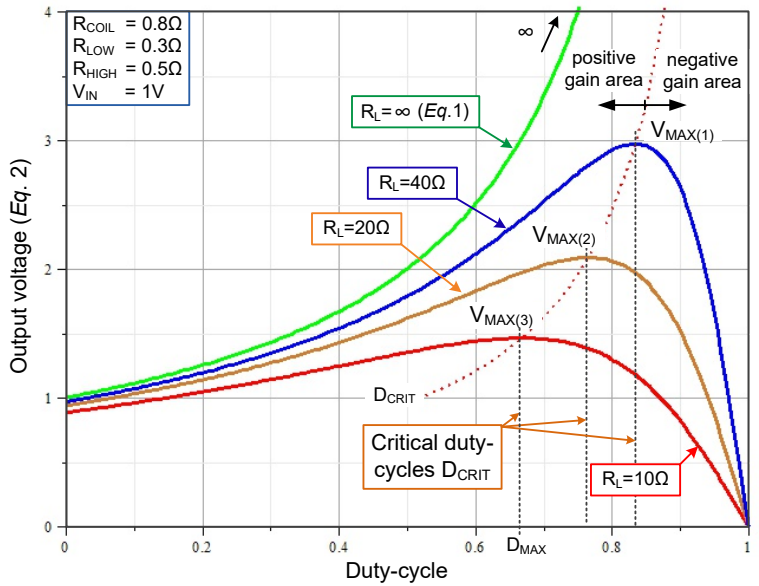

Fig. 5. $V_{\mathrm{OUT}} / V_{\mathrm{IN}} \mathrm{DC}$ voltage transfer function plotted with $E q .(8)$ [10].

$$
G_{C}=\frac{\left(R_{L}(1-D)^{2}-R_{\text {COIL }}-R_{\text {LOW }}\right) R_{L} V_{I N}}{\left(R_{L}(1-D)^{2}+D\left(R_{\text {LOW }}-R_{\text {HIGH }}\right)+R_{\text {COIL }}+R_{\text {HIGH }}\right)^{2}}
$$

A more accurate method allowing to obtain DC output voltage of real boost convertor is to use the power efficiency concept presented in [1]. This method assumes that power $P_{\mathrm{IN}}$ delivered by the input source is equal to the sum of output power $P_{\text {OUT }}$ and power $P_{\text {Loss }}$ dissipated in the converter:

$$
P_{\text {OUT }}=P_{I N}-P_{\text {LOSS }}
$$

This equation can be developed as the sum:

$$
\underbrace{V_{\text {OUT }} I_{\text {OUT }}}_{P_{\text {OUT }}}=\underbrace{V_{\text {IN }} I_{\text {COLL }}}_{P_{\text {IN }}}-\underbrace{I_{\text {COIL }}^{2}\left(R_{\text {COIL }}+D R_{\text {LOW }}+(1-D) R_{\text {HIGH }}\right)}_{P_{\text {LOSS }}}
$$

By expanding this expression with $I_{O U T}=V_{O U T} / R_{L}$, and $I_{C O I L}=I_{O U T} /(1-D)$, the output voltage from $(8)$ can be obtained. Advantageously, term $P_{\text {Loss }}$ can include other power-loss factors, which are not considered in Fig. 4 model. By this way, accuracy of $V_{\text {OUT }}$ can be improved e.g. by including ESR of $C_{\text {OUT }}$, MOSFETs switching power, high-side rectification diode nonlinear forward voltage drop, inductor frequency-dependent power loss, or power dissipated due to the inductor triangular (RMS) current.

\section{AC transfer Function}

The linearization of the averaged model allows also to build a small-signal model for the converter. Mainly, we can deliver the control-to-output transfer function $G_{\mathrm{C}}(\mathrm{s})=\hat{v}_{\mathrm{OUT}} / \hat{d}$ shown in Fig. 3, and the output impedance $Z_{\text {OUT }}(\mathrm{s})=\hat{v}_{\text {OUT }} / \hat{\imath}_{\text {OUT }}[6]$, [7] .

The linearization is performed for a given steady-state DC operating point $I_{\text {COIL }}, V_{\text {OUT }}$ and duty-cycle $D$. These values can be obtained either from expressions (1) and (2), or by more accurate (8) and (10). The AC signals produced by the controlled sources $v_{\mathrm{B}}$, and $i_{\mathrm{sw}(\mathrm{L})}$ can be written as:

$$
\begin{aligned}
& \hat{i}_{s w(L)}=\hat{d} \cdot I_{\text {COIL }}+D \cdot \hat{i}_{\text {COIL }}, \\
& \hat{v}_{B}=\hat{d} \cdot V_{\text {OUT }}+D \cdot \hat{v}_{\text {OUT }}-\hat{v}_{A}
\end{aligned}
$$

Here, $\wedge$ corresponds to $\mathrm{AC}$ voltages, and $\hat{d}$ is the $\mathrm{AC}$ excitation allowing to calculate the transfer function $G_{\mathrm{C}}(\mathrm{s})=\hat{v}_{\mathrm{OUT}} / \hat{d}$. The $\mathrm{AC}$ analysis of the Fig. 4 model with controlled sources defined by 
Eqs.(16) allow to obtain the transfer function, which is usually presented in the form [12], [14]:

$$
G_{C}(s)=\frac{\hat{v}_{O U T}}{\hat{d}} \cong G_{C} \frac{\left(1+s / z_{1}\right)\left(1-s / z_{2}\right)}{\frac{1}{\Omega_{0}^{2}}\left(s^{2}+\frac{\Omega_{0}}{Q} s+\Omega_{0}^{2}\right)}
$$

This control-to-output transfer function (17) contains two poles and two zeros: one in the left and one in the right-half-plane (RHP). Parameters of (17) are collected in Tab. $1\left(\Omega_{0}\right.$ and $Q$ calculated for $R_{\mathrm{LOW}}=$ $R_{\mathrm{HIGH}}=0$ ). Whereas, $G_{\mathrm{C}}$ is the static gain given by (3) or (13). Typically, the transfer function (17) is delivered for zero resistances $R_{\mathrm{LOW}}$ and $R_{\mathrm{HIGH}}$ [6], [12]. Although this achieves sufficient accuracy, a nonnegligible gain error can occur for high duty-cycle values. In order to improve the accuracy, complete DC and $\mathrm{AC}$ transfer functions corresponding to Fig. 4 model are presented in Tab. II.

The AC analysis of Fig. 4 model output node allows to extract the output impedance $Z_{\text {OUT }}$. This impedance allows to determine the shape of the load transient response, as shown in the example in section VI. D, $E q .(32)$. Calculation of $Z_{\text {OUT }}$ does not require steadystate values $I_{\text {COIL }}$ and $V_{\text {OUT }}$. Simplified form for $R_{\mathrm{LOW}}=R_{\mathrm{HIGH}}=0$ can be obtained as (see also Tab. II):

$$
Z_{\text {OUT }}(s)=\frac{R_{\text {COIL }}\left(1+E S R \cdot C_{\text {OUT }} s\right)}{(1-D)^{2}\left(1+E S R \cdot C_{\text {OUT }} s\right)+R_{\text {COIL }} C_{\text {OUT }} s}
$$

TABLE I.

\begin{tabular}{|c|c|c|}
\hline & Linear PWM generator & $\begin{array}{l}\begin{array}{l}\text { Modulated } \\
\text { generator }\end{array} \\
\text { ramp }\end{array}$ \\
\hline$z_{1}$ & $\frac{1}{R_{E S R} C_{\text {OUT }}}$ & $\frac{1}{R_{E S R} C_{\text {OUT }}}$ \\
\hline$z_{2}$ & $\frac{(1-D)^{2} R_{L}-R_{\text {COIL }}-R_{\text {LOW }}}{L}$ & $\frac{1}{L}\left(\frac{\alpha^{2} R_{L}}{I_{\text {CON }}^{2}}-R_{\text {COIL }}-R_{L O W}\right)$ \\
\hline$\Omega_{0}$ & $\sqrt{\frac{R_{\text {COIL }}+R_{L}(1-D)^{2}}{L C_{\text {OUT }}\left(R_{E S R}+R_{L}\right)}}$ & $\sqrt{\frac{\alpha^{2} R_{L} / I_{\text {CON }}^{2}+R_{\text {COIL }}}{L C_{\text {OUT }}\left(R_{L}+R_{E S R}\right)}}$ \\
\hline \multirow[b]{2}{*}{$Q$} & $\Omega_{0} L C_{\text {OUT }}\left(R_{L}+R_{E S R}\right)$ & $\Omega_{0} L C_{O U T}\left(R_{E S R}+R_{L}\right)$ \\
\hline & $\overline{C_{\text {OUT }} R_{L}\left(R_{E S R}(1-D)^{2}+R_{\text {COIL }}\right)+L}$ & $\overline{C_{\text {OUT }} R_{L}\left(R_{E S R}\left(\frac{\alpha}{I_{C O N}}\right)^{2}+R_{C O I L}\right)+L}$ \\
\hline
\end{tabular}

PARAMETERS OF CONTROL-TO-OUtPut TRANSFER FunCtion (17)

\section{Right-HALF Plane (RHP) ZERO AND DyNAMIC RESPONSE}

The positive $90^{\circ}$ phase lag of the Right-Half Plane zero of (17) constrains significantly the feedback control of the boost converter. It increases the high frequency phase lag of (17) to $-180^{\circ}$ (Fig. 3). The first reaction to a positive incremental step of $D$ is then a negative drop of the output voltage [13]. This is shown by transient simulation in Fig. 6. Here, a dutycycle increment of $\Delta D=+0.1$ was applied to a steadystate operating converter with $D=0.6$ and $I_{\text {OUT }}=100 \mathrm{~mA}$. Although the final output voltage increases by $+500 \mathrm{mV}$, the immediate response of $V_{\text {OUT }}$ is negative. Obviously, the response in wrong direction "confuses" the feedback controller and slows

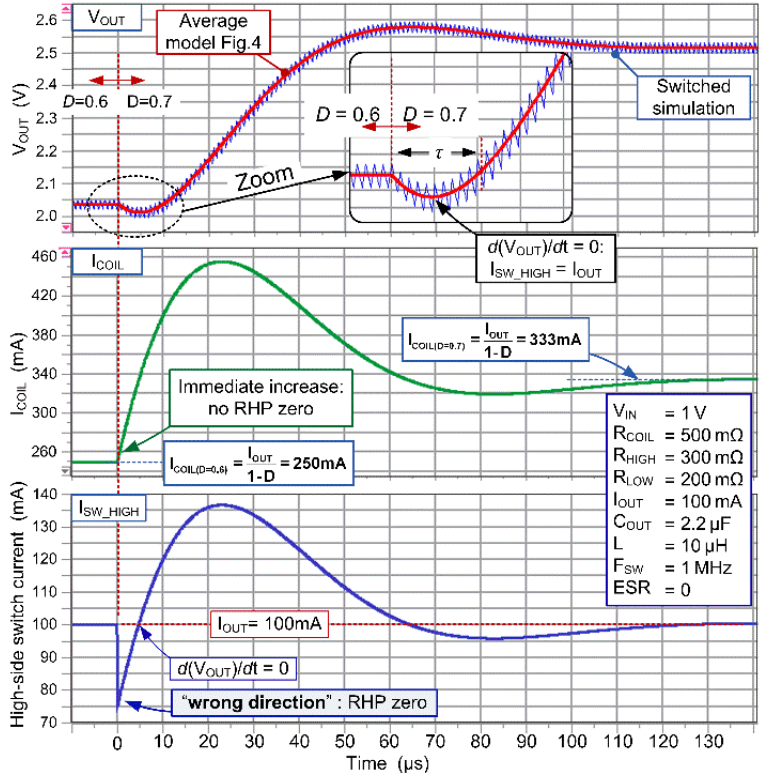

Fig. 6. Response of the boost converter to the increase of duty-cycle from $D=0.6 \rightarrow D=0.7$. Comparison of switched-mode and averaged models.

TABLE II.

Full MATLAB-COMPATIBLE EXPRESSIONS OBTAINED BY THE

\begin{tabular}{|c|c|}
\hline Eqs. & DC characteristics \\
\hline (8) & $\begin{array}{l}\text { Vout }=\mathrm{R} 1^{*}(1-\mathrm{D}) * \operatorname{Vin} /\left(\mathrm{R} 1^{*} \mathrm{D}^{\wedge} 2-\mathrm{D}^{*}(2 * \mathrm{R} 1+\right. \\
\text { Rhigh-Rlow })+\mathrm{Rhigh}+\mathrm{Rcoil}+\mathrm{R} 1)\end{array}$ \\
\hline$(10)$ & $\begin{array}{l}\text { Icoil }=\text { Vin } /\left(\mathrm{R} 1 * \mathrm{D}^{\wedge} 2-\mathrm{D}^{*}(2 * \mathrm{R} 1+\mathrm{Rhigh}-\right. \\
\text { Rlow })+\mathrm{Rhigh}+\mathrm{R} \text { coil }+\mathrm{Rl})\end{array}$ \\
\hline \multirow[t]{2}{*}{ (13) } & $\begin{array}{l}\mathbf{G c}=\operatorname{Vin} * \mathrm{R} 1^{*}\left(\mathrm{R} 1^{*}(1-\mathrm{D})^{\wedge} 2-\text { Rcoil-Rlow }\right) / \\
\left(\mathrm{R} 1^{*}(1-\mathrm{D})^{\wedge} 2+\mathrm{D}^{*}(\text { Rlow-Rhigh })+\text { Rhigh }\right. \\
+\mathrm{Rcoil})^{\wedge} 2\end{array}$ \\
\hline & Full-accuracy AC characteristics \\
\hline (17) & 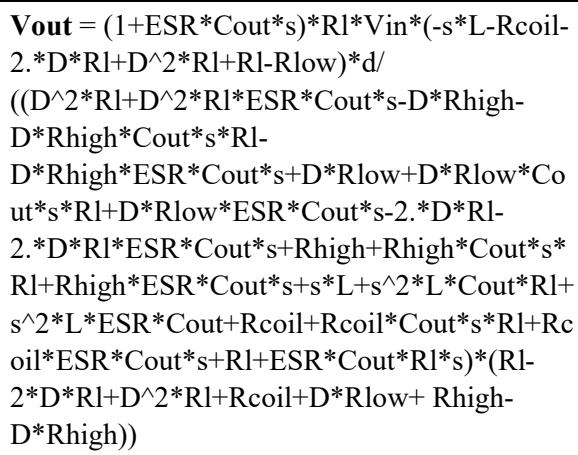 \\
\hline$(18)$ & $\begin{array}{l}\text { Zout }=\left(D^{*}(\text { Rlow-Rhigh })+\text { Rhigh }+ \text { Rcoil }+\right. \\
\left(D^{*}(\text { Rlow-Rhigh })+\text { Rhigh }+ \text { Rcoil }\right) * \text { ESR } * \text { Cout } \\
\left.*^{*}\right) /\left((1-D)^{\wedge} 2+\left(D^{*}(\text { Rlow-Rhigh })+\text { Rhigh }+\right.\right. \\
\left.\left.\text { Rcoil+ESR*(1-D })^{\wedge} 2\right)^{*} \text { Cout*s }\right)\end{array}$ \\
\hline (26) & $\begin{array}{l}\text { Vout }=\mathrm{RL}^{*} \text { alfa*Vin*Icon/(Rcoil*Icon`2* } \\
(\text { Rcoil }+ \text { Rlow })+(\text { Rhigh-Rlow)*Icon*alfa } \\
\left.+\mathrm{RL}^{*} \text { alfa^}^{\wedge}\right)\end{array}$ \\
\hline$(27)$ & 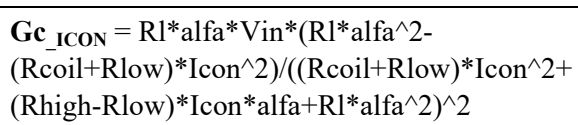 \\
\hline
\end{tabular}
ANALYSIS OF THE FIG. 4 AVERAGED-SWITCH MODEL. 
down the recovery of the output voltage. Unfortunately, RHP zero cannot be eliminated by control methods like current-mode control [17].

The understanding of the RHP zero can be made easier writing down the inductor current transfer function $I_{\mathrm{COIL}}(\mathrm{s}) / D(\mathrm{~s})$, obtained from the averaged model Fig. 4:

$$
I_{\text {COIL }}(s)=\frac{V_{I N}}{L(1-D)} \frac{\left(s+2 /\left(R_{L} C_{\text {OUT }}\right)\right)}{\left(s^{2}+\Omega_{0} / Q+\Omega_{0}^{2}\right)}
$$

Interestingly, $I_{\text {COIL }}(\mathrm{s})$ does not contain the RHP zero. This signifies that a positive increment $\Delta D$ produce an immediate (but slow) increase of $I_{\text {COIL }}(\mathrm{t})$. Indeed, the inductor current in Fig. 6 increases, in $\sim 100 \mu \mathrm{s}$, from an initial value of $250 \mathrm{~mA}$ up to the final steady-state value of $333 \mathrm{~mA}\left(I_{\mathrm{OUT}}=100 \mathrm{~mA}, E q .(2)\right)$. Compared to this, duty-cycle increment $\Delta D=0.1$ reduces instantaneously the high-side switch conduction time. As a result, $I_{\mathrm{SW} \text { HIGH }}$ drops by $25 \%$ at the transition time. The output capacitor is therefore discharged by a current equal to $I_{\mathrm{SW}-\mathrm{HIGH}}-I_{\mathrm{OUT}}$. This discharge continues until the high-side switch deliver full load current, i.e. $I_{\mathrm{SW} \_\mathrm{HIGH}}=I_{\mathrm{OUT}}=100 \mathrm{~mA}$.

Recovery time $\tau$ due to RHP zero can be reduced by maximizing its frequency $\left(z_{2}\right.$ in $\left.T a b . I\right)$. In particular, inductor value $L, R_{\mathrm{COIL}}$ and $R_{\mathrm{LOW}}$ are to be reduced. Similarly, it is preferable to make the converter operating at low duty-cycle. On the other hand, $C_{\text {OUT }}$ does not have an impact on $\tau$.

It is interesting to mention that $\Omega_{0}$ of $I_{\mathrm{COIL}}(\mathrm{s})$ and $V_{\text {OUT }}(\mathrm{s})$ given by Eqs.(19) and (17) are identical. However, quality factor $Q$ of (17) and (19) are different. Particularly $I_{\text {COIL }}(\mathrm{s})$ reaches a higher value: $Q_{(19)}=\Omega_{0} L C_{\text {OUT }} R_{L} /\left(L+R_{\text {COIL }} C_{\text {OUT }} R_{L}\right)$. It results that inductor current can reach a very-high (dangerous) value during the transient event.

Generally speaking, the poor transient-response of the boost converter operating at high duty-cycle results from Eq.(2), and it is due to a too short high-side switch conduction time. An increase of the inductor current $\Delta I_{\mathrm{COIL}}$ during e.g. load transient is considerably larger, when compared to buck converter. For instance, a $50 \mathrm{~mA}$ load transient step, with $D=0.7$, requires the inductor current to be increased by $\Delta I_{\mathrm{COIL}}=250 \mathrm{~mA}$. Obviously, reaching $\Delta I_{\text {COIL }}=250 \mathrm{~mA}$ takes a long time, resulting in large output voltage undershoot.

\section{LINEARIZATION OF THE BOOST CONVERTER}

Several approaches allowing either a partial or a complete linearization of the boost converter have been proposed in the past. Two of these techniques are commonly used:

- DC linearization by predistortion [14],[15], enabling to linearize the static DC transfer function (1), whereas the AC nonlinearity and RHP zero of transfer function (17) are not modified.

- Structural modification [16] allowing to obtain both linear static and linear dynamic transfer functions. Furthermore, this method removes the RHP zero from the control-to-output transfer function (17).
In the following sections, it will be shown that the linearization enable either a simple open-loop control of the boost converter, or provide stable closed-loop operations by using voltage-mode control scheme. Advantageously, the voltage-mode control does not require expensive current sensing, typically used by the current-mode control scheme [17]. This simplification is important for cost reduction, and it also allows obtaining good performances even in case of critical conditions (e.g. for low supply voltage).

\section{TRI-STATE SWITCHING BoOst CONVERTER}

As shown in section III, RHP zero and its initial undershoot occurs due to the high-side switch $\mathrm{SW}_{\mathrm{H}}$. It has been shown, that while duty cycle increment $\Delta D$ generates a slow increase of the inductor current, the reduction of the high-side switch $\mathrm{SW}_{\mathrm{H}}$ conduction time $T_{\mathrm{ON}(\mathrm{H})}$ produces an immediate drop of the current delivered to $C_{\text {OUT }}$ and to the load. Accordingly, RHP zero can be eliminated by keeping constant conduction time $T_{\mathrm{ON}(\mathrm{H})}$. Consequently, a control of the inductor current independent on $T_{\mathrm{ON}(\mathrm{H})}$ has to be implemented.

An obvious approach to control the inductor current is through the regulation of the input voltage $V_{\mathrm{IN}}$, while duty-cycle $D$ (i.e. $T_{\mathrm{ON}(\mathrm{H})}$ ) is maintained constant. This can be implemented by regulation of the input voltage $V_{\text {IN }}$ by an LDO regulator, or buck power stage. By doing so, converter then operates at high (constant) duty cycle $D$, but also with inductor current higher than $(2)$ - see below.

Alternatively, RHP zero elimination and DC linearization can be obtained for low output current by maintaining DCM operations [18].

\section{A. Tri-state Boost Converter}

A more straightforward way to control of the inductor current and maintain constant $T_{\mathrm{ON}(\mathrm{H})}$ is to use an additional switch $\mathrm{SW}_{\mathrm{AUX}}$. This configuration is labeled tri-state boost converter, and its basic schematic and related waveforms are shown in Fig. 7 $a, b)$ [16]. The voltage $V_{\mathrm{LX}}$ has three phases:

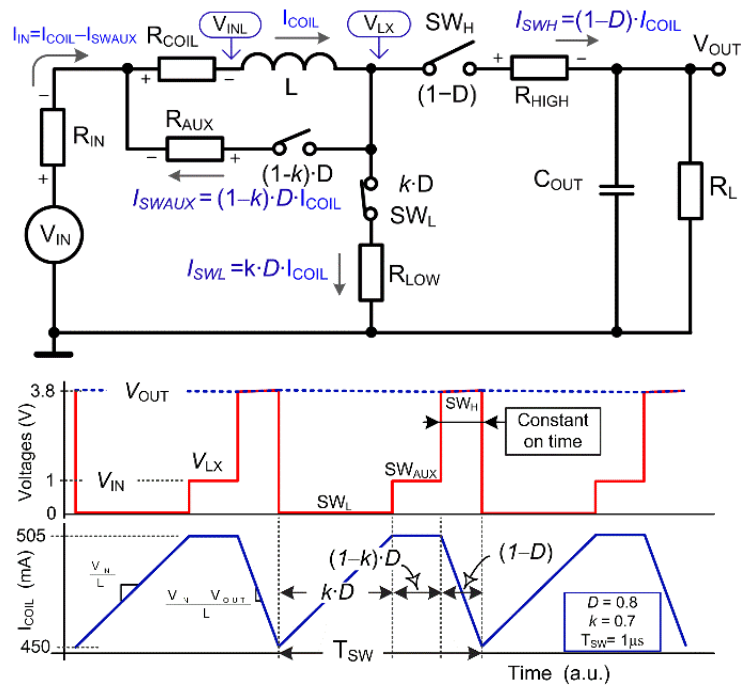

Fig. 7 a) Tri-state boost converter allowing to provide linear transfer function and eliminate RHP zero, $b$ ) main waveforms of the converter in $\mathrm{CCM}$. 
1) $\boldsymbol{k} \cdot \boldsymbol{D}: \mathrm{SW}_{\mathrm{L}}$ is closed and $V_{\mathrm{LX}}=0 \mathrm{~V}$. $I_{\mathrm{COIL}}$ increases linearly with slope $V_{\mathrm{IN}} / L$.

2) $(\boldsymbol{1}-\boldsymbol{k}) \boldsymbol{D}: \mathrm{SW}_{\mathrm{AUX}}$ is closed and $V_{\mathrm{LX}}=V_{\mathrm{IN}}$. In $\mathrm{CCM}$, the inductor current remains constant due to $\int V_{L} d t=0$.

3) $(\mathbf{1}-\boldsymbol{D}): \mathrm{SW}_{\mathrm{H}}$ is closed and $V_{\mathrm{LX}}=V_{\text {OUT }}$. Inductor current $I_{\mathrm{COIL}}$ linearly decreases with slope of $\left(V_{I N}-V_{O U T}\right) / L$.

Considering $k=1, \mathrm{SW}_{\mathrm{AUX}}$ is always open and converter behaves as standard boost converter from Fig. 1. The value of constant duty-cycle $D$ value can be then obtained from highest required conversion $V_{\text {OUT(MAX) }} / V_{\text {IN }}$ given by Eqs. (1) or (8). While lower $V_{\text {OUT }}$ is required, $k<1$ and $\mathrm{SW}_{\mathrm{AUX}}$ is closed during time $(1-k) D \cdot T_{\mathrm{SW}}$. Ratio $k<1$ is then used to control the inductor current without modifying the conduction time of high-side switch $\mathrm{SW}_{\mathrm{H}}$.

\section{B. Linear DC Transfer Function}

The output voltage $V_{\text {OUT }}$ can be obtained by applying the volt-second balance (4). The inductor voltage can be written as:

$$
k \cdot D\left(V_{I N}\right)+(1-k) D \cdot(0)+(1-D)\left(V_{I N}-V_{\text {OUT }}\right)=0
$$

and the output voltage can be written in the form:

$$
V_{\text {OUT }}=\left(1+\frac{D}{1-D} \cdot k\right) V_{I N}
$$

Here, we can see that $V_{\text {OUT }}$ is a linear function of $k$. The inductor current can be obtained as a function of the load as:

$$
I_{\text {COIL }}=\frac{I_{\text {OUT }}}{1-D}=\frac{V_{I N}}{(1-D) R_{L}}\left(1+\frac{D}{1-D} \cdot k\right)
$$

The behavior of the tri-state boost converter is demonstrated in Fig. 8 by sweeping the input control signal $k$ in the range 0 to 1 , with fixed $D=0.8$. Fig. 8 shows the DC characteristics obtained with ideal $\left(R_{\mathrm{COIL}}, R_{\mathrm{AUX}}, R_{\mathrm{LOW}}, R_{\mathrm{HIGH}}=0\right)$ and real model of the boost converter. We can notice that very high linearity is provided even for real converter simulation case.

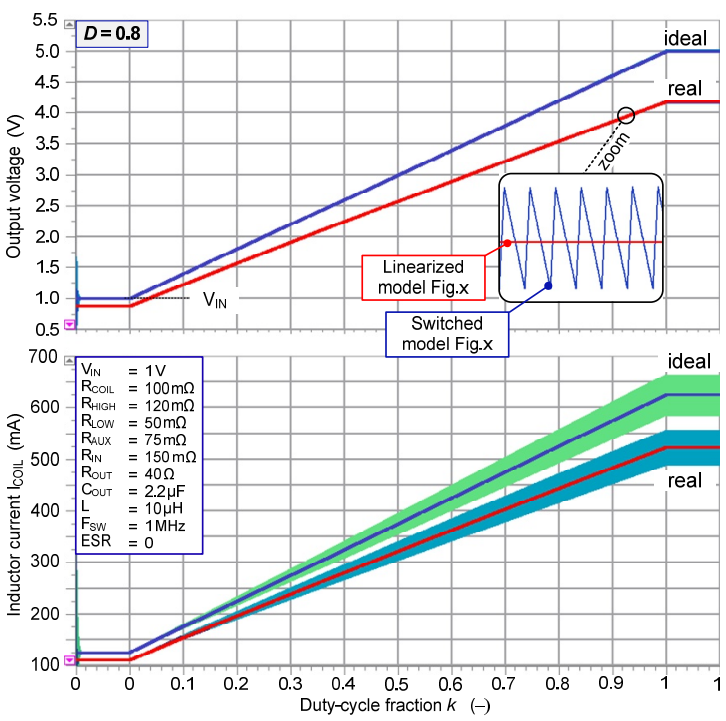

Fig. 8. DC transfer characteristics of $V_{\text {OUT }}$ and $I_{\text {OUT }}$ for $k$ varying from 0 to 1 of real and ideal $\left(R_{\mathrm{COIL}}, R_{\mathrm{AUX}}, R_{\mathrm{LOW}}, R_{\mathrm{HIGH}}=0\right)$ tri-state boost converter. Comparison of switched-model Fig. 7, and averaged-switches model Fig. 9.

\section{Averaged Switch Model}

Similarly as presented in section II. A, the volt-second balance was applied to the nonideal tri-state converter shown in Fig. 7. The obtained average switch model shown in Fig. 9 allows to perform both AC and DC simulations. The additional switching state of $\mathrm{SW}_{\mathrm{AUX}}$ is represented in Fig. 9 by $\left\langle i_{\mathrm{AUX}}\right\rangle$. Second current source $\left\langle i_{\mathrm{AUX}}\right\rangle$ is used to provide $\left\langle v_{\mathrm{AUX}}\right\rangle$ referred to GND. Different inductor and input source currents highlighted in Fig. 7 a) does not allow to include DC source resistance $R_{\mathrm{IN}}$ into $R_{\mathrm{COIL}}$. On this account, $R_{\mathrm{IN}}$ was added to the circuits in Figs. 7 and 9.

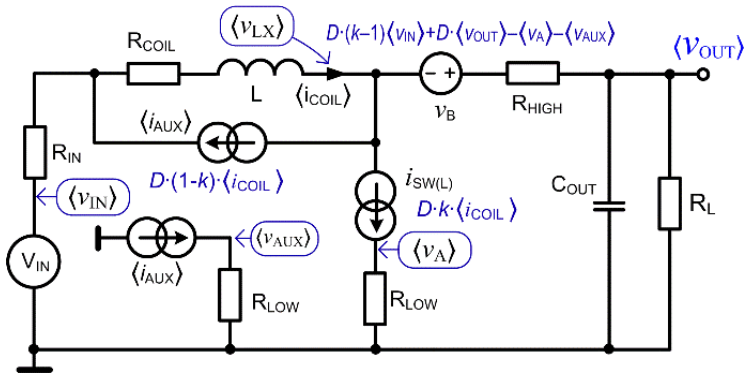

Fig. 9. Averaged switches model with VCVS and CCCS of the tristate boost converter from Fig. 7 .

A comparison between linear and switched model of the tri-state boost converter is shown in Fig. 8. The simulation of AC transfer function can be obtained by considering $k=k+\hat{k}$, whereas $\hat{k}$ is the AC signal input $\mathrm{AC}=1$.

Load transient behavior of the tri-state boost converter is shown in next section in Fig. 16. Here, we notice that undershot and global shape of the transient response is almost independent of the conversion ratio $k$. Note: for zero switches and inductor resistances, the transient characteristics will be exactly identical for all duty-cycles. It result, that control-tooutput transfer function is no more dependent on $D$ and $R_{\mathrm{L}}$, and belongs to the LTI (linear-time invariant) class of systems.

\section{Power-Efficiency Consideration}

Important benefit of the DC linearization and RHP zero elimination is paid by higher inductor current, given by (22). As an example, tri-state converter operating at $D=0.8$ and $k=0.5$ result in three-time higher $I_{\text {COIL }}$ than boost converter from Fig. 1 with identical $V_{\text {OUT. }}$. Consequently, $I_{\text {COIL }}^{2}$ leads to approximately nine-time higher power loss when compared to the standard boost converter.

\section{RAMP-MOdUlated PWM Generator With BATTERY VOLTAGE FEEDFORWARD}

Second class of the linearization method allowing to achieve constant DC gain $\left(G_{\mathrm{C}}\right)$ is the PWM predistortion. Predistortion aims to provide nonlinear duty-cycle generation, that compensate the original DC nonlinearity of the boost converter (1). On the contrary, nonlinear dynamic of the boost converter remains unchanged. This means, that predistortion preserves both poles and RHP zero of the control-tooutput transfer function mowing with $D$ and $R_{\mathrm{L}}$ (as mentioned in Tab.I. and shown in Fig. 3). This situation is demonstrated by frequency characteristics shown in Fig. 10 [14]. 


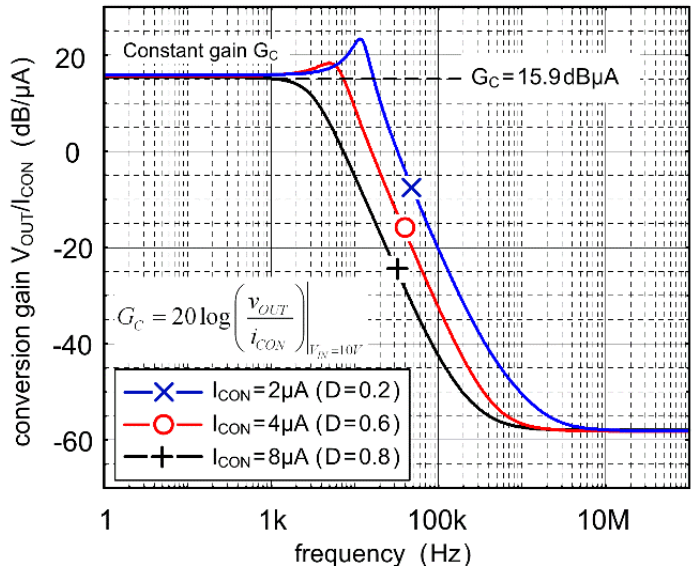

Fig. 10. Control-to-Output transfer functions of ramp-modulated boost converter [14]. Simulation parameters are: $V_{\mathrm{IN}}=10 \mathrm{~V}, L=$ $5 \mu \mathrm{H}, \mathrm{C}=22 \mu \mathrm{F}, R_{\text {COIL }}=150 \mathrm{~m} \Omega, \mathrm{ESR}=20 \mathrm{~m} \Omega, R_{\mathrm{L}}=100 \Omega V_{\mathrm{b}}=$ $0.5 \mathrm{~V}, C=1 \mathrm{pF}, T=0.3125 \mu \mathrm{s}(\alpha=1.6 \mu \mathrm{A}), R_{\mathrm{LOW}}=R_{\mathrm{HIGH}}=0$.

Main benefit of the predistortion is the compatibility with existing boost converter power stage. Moreover, predistortion partially linearize the converter without power efficiency loss as discussed in section $V$. D.

The predistortion is usually implemented inside the PWM modulator. The predistortion is either based on an inner modulator feedback loop [15], or on direct predistortion described further below. The advantage of direct predistortion is a faster response of the modulator, which does not alter the feedback loop by adding extra poles. As mentioned in [14], the predistortion can be advantageously used also for other architectures such as buck-boost or flyback.

\section{A. Pre-distorted PWM Modulator Circuit}

The PWM predistortion described in this section allows to obtain a linear $V_{\mathrm{OUT}} / V_{\mathrm{IN}}$ conversion characteristic, and also to provide battery voltage feedforward. This means that, for given input control signal (e.g. $\left.V_{\text {ERROR }}\right)$, the boost converter output voltage $V_{\text {OUT }}$ is ideally independent of input (battery) voltage $V_{\mathrm{IN}}$. Advantageously, this improves line-transients regulation.

The technique of predistortion was originally presented by Arbetter and Maksimovic [19] in 1995. Then, the battery voltage feedforward was reinvented by Kazimierczuk 1997 [20], PWM predistortion by Egawa 2010 [21], and finally also by the author of this paper in 2012 [14].

Main concept of the ramp-modulated PWM generator is shown in Fig. 11. Here, the input control signal $\left(V_{\text {ERROR }}\right)$ is applied to the current source $I_{\mathrm{CON}}$. For instance, $I_{\mathrm{CON}}$ is directly proportional to the PID controller output voltage $V_{\text {ERROR }}$. As a result, the ramp amplitude is proportional to the control signal. The variable ramp amplitude $V_{\mathrm{C}}$ is shown in Fig. 12 .

The duty-cycle $\mathrm{D}$ generated by the modulator can be determined from the time analysis of capacitor voltage $V_{\mathrm{C}}(t)$. As indicated in Fig. 12, current $I_{\mathrm{CON}}$ (considered constant during one clock period $T$ ) generates the voltage $V_{C}(t)=\left(I_{C O N} / C\right) t$. The capacitor voltage is then compared with an arbitrary reference voltage $V_{\mathrm{b}}$. While the capacitor is periodically discharged with period $T$, the duty-cycle $D$ is defined within the condition $I_{C O N(\min )}>V_{b} \cdot C / T$ as:

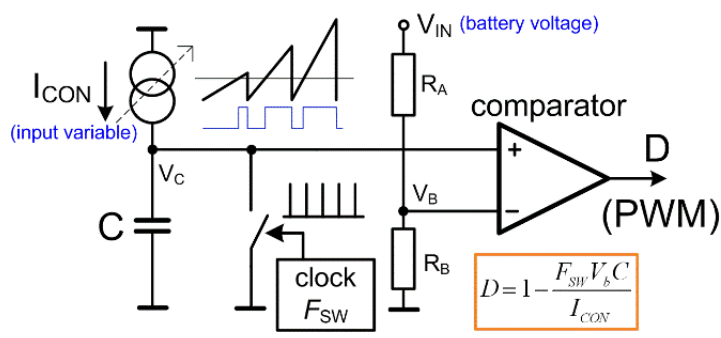

Fig. 11. Nonlinear modulated-ramp PWM generator [14],[19].

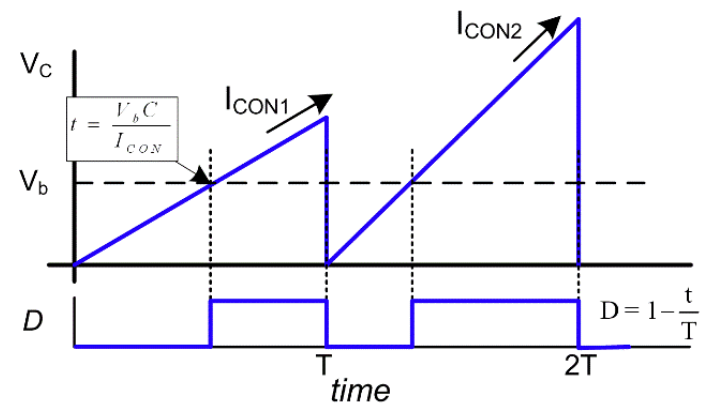

Fig. 12. Capacitor voltage $V_{\mathrm{C}}(t)$ for two values of $I_{\mathrm{CON} 1}$ and $I_{\mathrm{CON} 2}$ [14]. $I_{\mathrm{CON}}$ is considered constant during one clock period.

$$
D=1-\frac{V_{b} C}{I_{C O N} T}=1-\frac{\alpha}{I_{C O N}}
$$

\section{B. DC Output Voltage with Feedforward}

The relationship (23) between duty-cycle $D$ and control current $I_{\mathrm{CON}}$ can be substituted in the conversion characteristic (1). As a result, the output voltage is a linear function of $I_{\mathrm{CON}}$ :

$$
V_{\text {OUT }}=\frac{I_{C O N} T}{V_{b} C} V_{I N}
$$

Moreover, if the term $V_{\mathrm{b}}$ in (24) is proportional to input voltage $V_{\mathrm{IN}}\left(e . g . V_{b}=k \cdot V_{I N}\right)$, the term $V_{\mathrm{IN}}$ can be eliminated from (24). This realizes the so-called "battery-voltage feedforward":

$$
V_{\text {OUT }}=\frac{I_{C O N} T}{k \cdot V_{I N} C} V_{I N}=I_{C O N} \frac{T}{k \cdot C}
$$

The output voltage is then only determined by the clock frequency, the ramp capacitor and the control

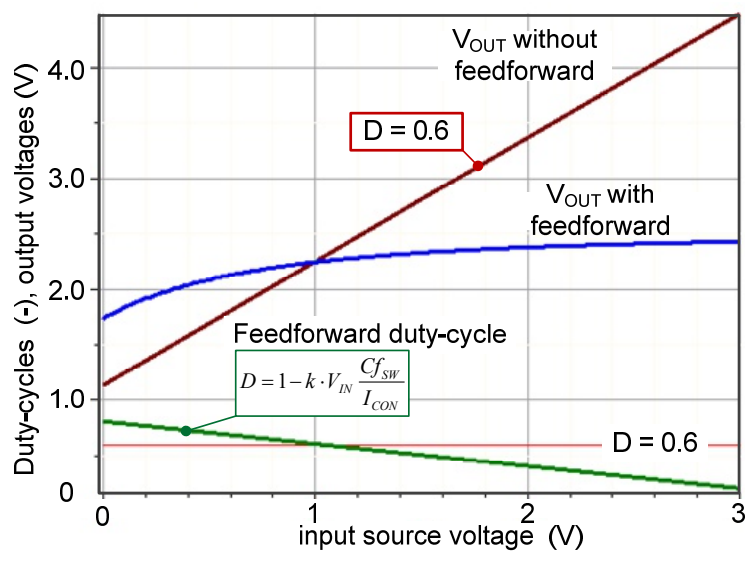

Fig. 13. Example of comparison between boost converter with fixed duty-cycle $D=0.6$, and battery voltage feedforward with parameters: $C=15 \mathrm{pF}, k=0.25, f_{\mathrm{SW}}=1 \mathrm{MHz}, I_{\mathrm{CON}}=9.375 \mu \mathrm{A}, R_{\mathrm{COIL}}$ $=500 \mathrm{~m} \Omega, R_{\mathrm{HIGH}}=300 \mathrm{~m} \Omega, R_{\mathrm{LOW}}=200 \mathrm{~m} \Omega$, and $R_{\mathrm{L}}=40 \Omega$. 
current $I_{\mathrm{CON}}$. On the other hand, $V_{\mathrm{OUT}}$ is independent of $V_{\mathrm{IN}}$. An example of comparison between boost converter with fixed duty-cycle, and battery voltage feedforward is shown in Fig. 13.

For a real boost converter with predistortion, the output voltage can be obtained by inserting the equation of $D(23)$ into (8). This results in:

$$
V_{\text {OUT }}=\frac{\alpha I_{\text {CON }} R_{L}}{I_{\text {CON }}^{2}\left(R_{\text {COIL }}+R_{\text {LOW }}\right)-\alpha I_{\text {CON }}\left(R_{H I G H}-R_{\text {LOW }}\right)+R_{L} \alpha^{2}}
$$

The derivative of (26) for $R_{\mathrm{HIGH}}=R_{\mathrm{LOW}}=0$ allows to obtain DC gain $\left(G_{\mathrm{C}_{-} \text {ICON }}\right)$ :

$$
G_{C_{-} I C O N}=\frac{\partial V_{\text {OUT }}}{\partial I_{C O N}}=\frac{V_{I N}}{\alpha} \frac{1-\frac{R_{C O I L} I_{C O N}^{2}}{\alpha^{2} R_{L O A D}}}{\left(1+\frac{R_{C O L L} I_{C O N}^{2}}{\alpha^{2} R_{L O A D}}\right)^{2}}
$$

More accurate equations (26) and (27) including $R_{\mathrm{HIGH}}$ and $R_{\mathrm{LOW}}$ are available in Tab. $I I$.

An example of $V_{\mathrm{OUT}} / V_{\mathrm{IN}}$ conversion characteristics for both ideal and real boost converters with rampmodulated PWM generator are shown in Fig. 14. Here, we can notice a small decrease of the output voltage for high values of $I_{\mathrm{CON}}$. Advantageously, when compared to the abrupt decrease of $V_{\text {OUT }}$ above the $D_{\text {CRIT }}$ in Fig. 5, smooth decrease of $V_{\text {OUT }}$ with rampmodulated PWM generator crates a natural duty-cycle limitation preventing the inversion of the conversion gain [10].

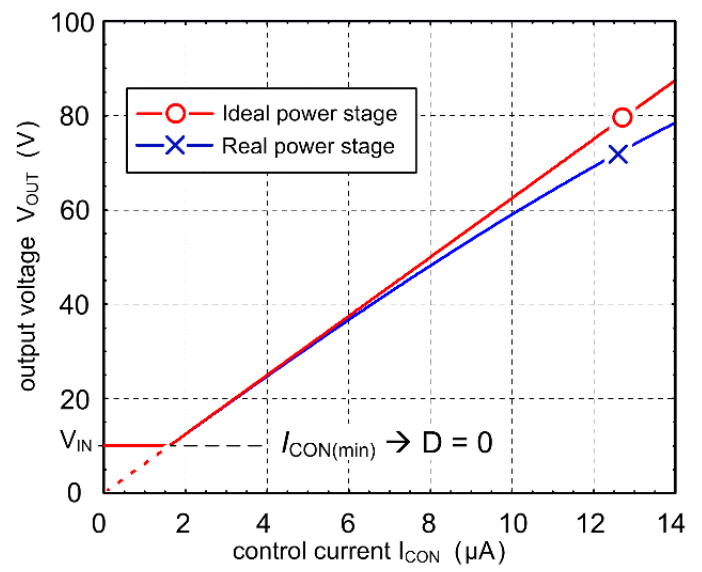

Fig. 14. Comparison of ideal $\left(R_{\mathrm{L}}=0\right)$ and real $\left(R_{L}=150 \mathrm{~m} \Omega\right)$ boost converter conversion characteristics with modulated-ramp PWM generator $\left(V_{I N}=10 \mathrm{~V} V_{\mathrm{b}}=0.5 \mathrm{~V}, R_{L}=150 \mathrm{~m} \Omega, R=100 \Omega, C=1 \mathrm{pF}\right.$, $T=0.3125 \mu$ s or $\alpha=1.6 \mu \mathrm{A}$.

\section{AC Characteristics}

As already mentioned, the predistortion technique achieved by the modulated-ramp generator does not modify the nonlinear dynamic behavior. This means that the transfer function (17) remains unchanged, except for the DC gain $G_{\text {C_ICON }}(27)$. Both values of poles and zeros can be obtained as a function of $I_{\mathrm{CON}}$ replacing the duty cycle (23) into the values from Tab. I. (left). Resulting values are mentioned for $R_{\mathrm{LOW}}=R_{\mathrm{HIGH}}=0$ in TabI (right). Final control-tooutput transfer function can be then obtained by $i$ ) substituting values from Tab. I. right, and ii) gain $G_{\text {C_ICON }}$ (27) (Tab. II.) into (17). An example of control-to-output transfer functions bode plots for three values of duty-cycle is shown in Fig. 10.

D. Voltage-mode Feedback Control Loop: Example.

An example of the voltage-mode feedback control loop is shown in Fig. 15. Here, the output voltage of PID controller $V_{\text {ERROR }}$ [22] is connected to a V/I converter with conversion gain $1 / R_{\mathrm{v} 2 \mathrm{i}}\left(\Omega^{-1}\right)$. This PID controller exhibits a transfer function:

$$
\begin{array}{r}
F_{P I D}(s)=\frac{1+\left(R_{B} C_{1}+C_{1} R_{1}+C_{2} R_{2}\right) s+\left(R_{B}+R_{1}\right) C_{2} C_{1} R_{2} s^{2}}{s R_{B} C_{2}\left(C_{1} R_{1} s+1\right)} \\
=G_{0} \frac{\left(s / z_{1}+1\right)\left(s / z_{2}+1\right)}{s \cdot\left(s / p_{1}+1\right)}
\end{array}
$$

As shown in Fig. 15, the pre-distorted PWM generator then drives a standard boost converter from Fig. 1. For convenience, this scheme also contains the tri-state simulation case used in the demonstration in next section.

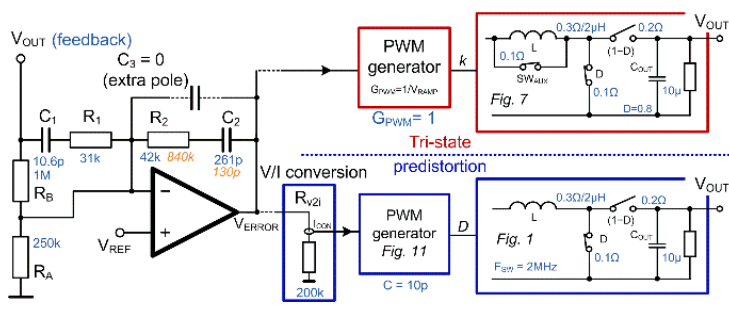

Fig. 15. Simulation scheme of the Voltage mode feedback loop of the tri-state and pre-distorted boost converter.

During the design phase of the PID controller, the double pole of the transfer function (17) can be eliminated by double zero of the controller (28). On the other hand, RHP zero $z_{2}$ is eliminated by the controller pole. Obviously, this cancellation is not mathematically possible, but allows to obtain sufficient starting point for the final PID controller parameter adjusting. The Open-loop transfer function $F_{P I D}(s) K_{V / I} G_{C}(s)$ is then:

$F_{O L}(s) \cong \frac{1}{R_{v 2 i}} \underbrace{\left.G_{0} \frac{\left(s / z_{P I D_{-}}+1\right)}{s \cdot\left(s / z_{P I D_{-}}+1\right)}+1\right)}_{F_{P D D}(s)} \underbrace{G_{C_{-} I C O N} \frac{\Omega_{0}^{2}\left(1 .-s / z_{2}\right)}{\left(1+s<\Omega_{0}\right)^{2}}}_{F_{\text {BOOST }}}$

Here, the quality factor $Q$ of (17) was considered $1 / 2$, and the zero coming from ESR was neglected. The resulting transfer function is of a first order:

$$
F_{O L}(s)=2 \pi B W / s
$$

where $B W$ is the open loop bandwidth of the loop. This bandwidth is used as a starting-point parameter for the feedback loop transfer function synthesis. By equaling (29) and (30), the PID controller DC gain $G_{0}$ can be obtained as a function of the bandwidth, $G_{\mathrm{C} \_ \text {ICON }}$ and $R_{\mathrm{v} 2 \mathrm{i}}$ : as:

$$
G_{0}=2 \pi B W \cdot R_{v 2 i} / G_{C_{-} I C O N}
$$

By several iterations of $B W$, suitable PID controller transfer function can be obtained. As previously mentioned, PID controller zeros are $z_{\mathrm{PID}-1}=z_{\mathrm{PID}-2}=\Omega_{0}$, and $p_{\text {PID-1 }}=z_{2} \quad(T a b .1)$. The values of passive components can be computed by comparing the coefficients of $F_{\mathrm{PID}}(\mathrm{s})$ with the transfer function (28) see ref. [22], or Tab. III. 
A Matlab algorithm allowing a fast computation of the PID controller values for a given duty-cycle (e.g. $D=$ $0.6)$, the visualization of gain/phase margins and the load and $V_{\text {REF }}$ transients, is presented in Tab III. The load transient response used in the algorithm is obtained by the help of output impedance (18) [23]:

$$
F_{L O A D}(s)=\frac{V_{\text {OUT }}(s)}{I_{\text {LOAD }}(s)}=\frac{Z_{\text {OUT }}}{1+G_{C_{-} I C O N}(s) G_{P I D}(s) / R_{v 2 i}}
$$

\section{COMPARISON OF THE LINEARIZATION METHODS}

The voltage model control loop was implemented for both boost converters with tri-state PWM and predistorted modulated ramp PWM generator. The simulation scheme is shown in Fig. 15. In order to provide a visible response for a $100 \mathrm{~mA}$ load step, the PID controller was designed for unreasonably low control-to-output transfer function bandwidth (30) $B W=500 \mathrm{~Hz}$ (Tab. III, D = 0.6, Fig. 15.).

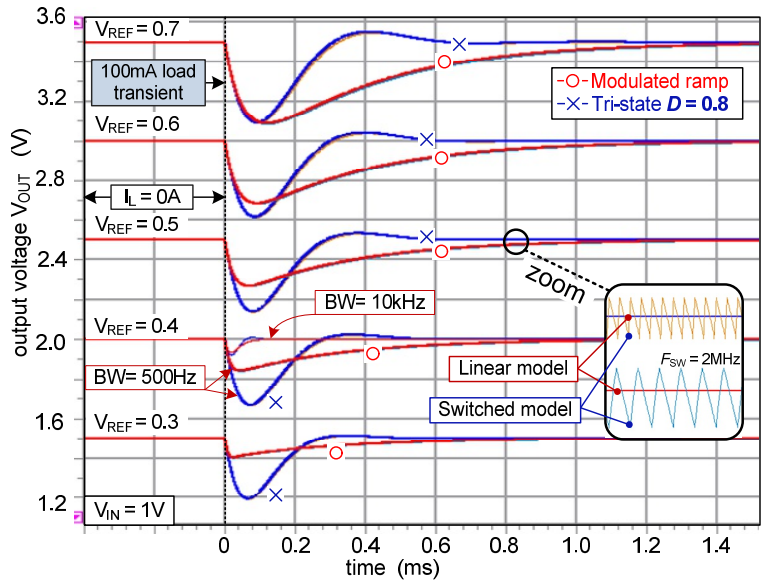

Fig. 16. Comparison of $100 \mathrm{~mA}$ load transient response for tri-state converter and converter with predistortion. Parameters of simulations are identical with parameters in Tab. III. except $B W=$ $500 \mathrm{~Hz}$, and $R_{\mathrm{AUX}}=0.1 \Omega$. Duty-cycle of tri-state converter $D=0.8$, i.e. $\left.\mathrm{T}_{\mathrm{SW}(\mathrm{H})}=100 \mathrm{~ns}\right)$.

Parameters of the PID controller for fast regulation scheme $(\mathrm{BW}=30 \mathrm{kHz})$ are shown in Fig. 15 in italic. One simulation results for $B W=30 \mathrm{kHz}$ is shown for $V_{\mathrm{REF}}=0.4 \mathrm{~V}$ in Fig. 16

From the transient responses shown in Fig. 16, we can notice that:

- Tri-state boost converter provide transient response almost independent of the duty-cycle $D$,

- Modulated ramp predistortion provide improving response with decreasing duty-cycle value (decreasing $V_{\text {OUT }}$ ).

This different behavior corresponds to the different level of linearization offered by each method. The tristate converter provides linearization of the complete transfer function, whereas the predistortion technique maintains the resonant frequency and other parameters of $G_{\mathrm{C}}(\mathrm{s})$ listed in Tab. 1 depending (sometimes favorably) on the duty-cycle $D$.

While the Tri-state boost converter operates with high (constant) duty-cycle $D=0.8$, the equivalent resonant frequency $\Omega_{0}$ is low. Therefore, despite the absence of RHP zero and higher inductor current, the transient
TABLE. III: MATLAB AlgORITHM FOR PID CONTROLLER DESIGN FOR THE PRE-DISTORTED BOOST CONVERTER.

close all; clear all; $\mathrm{s}=\mathrm{tf}($ 's');

$\mathrm{L}=\operatorname{input}\left({ }^{\mathrm{L}}(2 \mathrm{e}-6)={ }^{\prime}\right) ;$ Cout=input('C $\left.(10 \mathrm{e}-6)={ }^{\prime}\right)$;

Rcoil $=$ input ('Coil + Battery resistance $(0.3)=')$;

Rlow=input('Rlow $\left.(0.1)={ }^{\prime}\right)$; Rhigh=input('Rhigh $(0.2)=$ ');

$\mathrm{RL}=\operatorname{input}(\mathrm{RL}(40)=$ '); ESR=input('ESR $(0.02)=$ ');

Rv2 $\mathrm{i}=$ input('V/I converter resistance $(200 \mathrm{e} 3)=')$;

Vin=input('Vin $(1)=')$;

BW=input('Open-loop bandwidt $(10000)=')$;

$\mathrm{k}=$ input('feedforward ratio $(0.25)=$ ');

Cramp=input('pwm ram capacitor $(10 \mathrm{e}-12)=$ ');

Fsw=input('switching frequency $(2 \mathrm{e} 6)=$ ');

$\mathrm{D}=$ input('steady-stte duty-cycle $\left.\mathrm{D}(0.6)={ }^{\prime}\right)$;

$\%$ PID controller gain $\mathrm{G} 0$

$\mathrm{Vb}=\mathrm{k} * \mathrm{Vin} ; \mathrm{Icon}=-\mathrm{Vb} * \mathrm{Cramp} * \mathrm{Fsw} /(\mathrm{D}-1)$;

alfa $=\mathrm{k} *$ Vin*Cramp*Fsw;

$\mathrm{Gc}=\mathrm{RL} *$ alfa*Vin $*(\mathrm{RL} *$ alfa^2-

$(\text { Rcoil+Rlow })^{*}$ Icon $\left.^{\wedge} 2\right) /\left((\right.$ Rcoil + Rlow $) *$ Icon ${ }^{\wedge} 2+($ Rhigh-

Rlow)*Icon*alfa+RL*alfa^2)^2;

$\mathrm{G} 0=2 * \mathrm{pi}^{*} \mathrm{BW} * \mathrm{Rv} 2 \mathrm{i} / \mathrm{Gc}$

omega $=\operatorname{sqrt}\left(\left((1-\mathrm{D})^{\wedge} 2 * \mathrm{RL}+\mathrm{Rcoil}\right) / \mathrm{RL}\right) / \operatorname{sqrt}(\mathrm{L} *$ Cout $)$; ppid $=\left((1-D)^{\wedge} 2 * R L-R c o i l\right) / L$; ('PID transfer function');

$\mathrm{Fpid}=\mathrm{zpk}\left(\mathrm{G} 0 *(1+\mathrm{s} / \text { omega })^{\wedge} 2 /(\mathrm{s} *(1+\mathrm{s} / \mathrm{ppid}))\right)$

$\%$ GM, PM for D 0.1 to 0.9

for $\mathrm{n}=1: 8$;

$\mathrm{D}=0.1{ }^{*} \mathrm{n} ; \operatorname{Out}(\mathrm{n}, 1)=\mathrm{D}$;

$\operatorname{Out}(\mathrm{n}, 2)=-\mathrm{Vb} * \mathrm{Cramp} * \mathrm{Fsw} /(\mathrm{D}-1) ; \%$ Icon for D

$\operatorname{Out}(\mathrm{n}, 3)=\mathrm{RL} *$ alfa*Vin* $(\mathrm{RL} *$ alfa^ $2-$

(Rcoil+Rlow)*Out(n, 2)^2)/((Rcoil+Rlow)*Out(n,

$2)^{\wedge} 2+\left(\text { Rhigh-Rlow)* } \operatorname{Out}(\mathrm{n}, 2)^{*} \text { alfa }+\mathrm{RL}^{*} \text { alfa } 2\right)^{\wedge} 2 ; \%$ gain $\mathrm{Gc}$

$\%$ Transient, bode and gain and phase margins plots for $\mathrm{D}=0.1$ to 0.8

Fboost $=\mathrm{Gc} *(1+\mathrm{s} * \mathrm{ESR} *$ Cout $) *(1-\mathrm{s} * \mathrm{~L} /((1-\mathrm{D}) \wedge 2 * \mathrm{RL}-$ Rcoil) $) /(1+\mathrm{s} * \mathrm{~L} *$ Cout*RL*(Rcoil/L+1/(Cout*(RL+ESR $))$ )$\left./(\text { Rcoil }+(1-\mathrm{D}))^{\wedge} 2 * \mathrm{RL}\right)+\mathrm{s}^{\wedge} 2 * \mathrm{~L}^{*}$ Cout ${ }^{*} \mathrm{RL} /($ Rcoil $+(1-$ D)^ $2 * R L)$;

Fol=Fpid*Fboost/Rv2i; $\mathrm{Fcl}=\mathrm{Fol} /(1+\mathrm{Fol}) ;$

Zout $=\left(D^{*}(\right.$ Rlow - Rhigh $)+$ Rhigh + Rcoil $+\left(D^{*}(\right.$ Rlow-

Rhigh $)+$ Rhigh + Rcoil $) * \mathrm{ESR}^{*}$ Cout $\left.* \mathrm{~s}\right) /((1-$

D)^2+(D*(Rlow-Rhigh) + Rhigh + Rcoil + ESR $*(1-$

D)^2)*Cout*s);

FLoad_tran=Zout $/(1+\mathrm{Fol})$;

[Out(n,4),Out(n,5)]=margin(Fol); \%Out(n,4) - gain

margin Out $(n, 5)$ - phase margin

$\operatorname{Out}(\mathrm{n}, 4)=20 * \log 10(\operatorname{Out}(\mathrm{n}, 4))$;

figure(1); step(Fcl); grid on; hold on; title('control to output transient');

figure(2); bode(Fol); grid on; hold on; title('Open-loop transfer function');

figure(3); step(-FLoad tran); grid on; hold on; title('1A Load Transient (with linearized TF)');

$\mathrm{n}=\mathrm{n}+1$;

end

figure(4); plot(Out(:,1),Out(:,4)); grid on

title('Gain margin (dB) vs. Duty-cycle')

figure(5); $\operatorname{plot}(\operatorname{Out}(:, 1), \operatorname{Out}(:, 5))$; grid on

title('Phase margin (degre) vs. Duty-cycle')

figure(6); bode(Fpid); grid on;

title('PID bode plot - check the gain at Fsw $(<20 \mathrm{~dB})$ ')

('computation of passive components');

RA = input('choose Ra (e.g. 250000) ='); Vref =

input('Choose Vref (e.g. 0.4)=');

Vout $=$ input('Choose Vout (e.g. 2) $=$ ');

$\mathrm{RA}=\mathrm{RA}, \mathrm{RB}=\mathrm{RA} *($ Vout-Vref $) /$ Vref, $\mathrm{R} 1=$

RA*omega*(Vout-Vref)/((omega-ppid)*Vref),

$\mathrm{R} 2=($ Vout-Vref) $* \mathrm{RA} * \mathrm{G} 0 /($ Vref*omega $), \mathrm{C} 1=-($ omegappid)*Vref/(RA*omega*ppid*(Vout-Vref)),

$\mathrm{C} 2=$ Vref $/\left(\mathrm{RA}^{*} \mathrm{G} 0 *(\right.$ Vout - Vref $)$ 
response is not significantly improved in Fig. 16, when compared to the predistortion (for similar openloop BW). However, the Tri-state boost converter is better in some configurations, (high value of $L$, that could create very low-frequency RHP zero), where a stable boost converter can be difficult to design in a wide duty-cycle range with only the predistortion technique.

\section{CONCLUSION}

This paper presents a tutorial on the nonlinear behavior, modeling, and linearization of the boost converter. It aims to provide a compact introduction to the topic with insight on the mathematical description and models, being useful with help of standard CAD environment. It also presents an application example of the boost converter in pure voltage mode, which allows to provide a stable behavior and good quality of the regulation in a wide range of operation parameters.

\section{REFERENCES}

[1] M. K. Kazimierczuk, "Pulse-Width Modulated DC-DC Power Converters", Willey, $2^{\text {nd }}$ edition 2015.

[2] H. J. Zhang, "Modeling and loop compensation design of switch mode power supplies," Application note 149, Linear Technology, 2015.

[3] K. I. Hwu, Y.T. Yau, " Performance enhancement of boost converter based on PID controller plus linear-to-nonlinear translator," IEEE transactions on powe electronics, vol. 25, No. 52010.

[4] M. K. Kazimierczuk, N. Kondrath, "control-to-output and duty ratio-to-inductor current transfer function of peak currentmode controlled dc-dc PWM buck converter in CCM," in proc. of IEEE conf. Circuit and Systems ISCAS, 2010, pp. $2734-2737$.

[5] Z. Kolka, D. Biolek, J. Kovar, "On accuracy of averaged control-to-output frequency responses of switched DC-DC converters," in proc. of 20th IEEE conference Radioelektronika, 2010.

[6] V. Vorperian, "Simplified analysis of PWM converters using the model of the PWM switch, Part I: Continuous conduction mode," in IEEE trans. of Aerospace and Electronic Systems, vol.AES-26,, May 1990.

[7] E. Dijk, J.N. Spruijt, M.O. Sulilivan, J.B. Klaassens, "PWM switch modeling of DC-DC converters," IEEE Trans. on power electronics, vol. 10, no. 6, 1995, pp. 659-66.

[8] A. Ayachit, A. Reatti, M.K. Kazimierczuk, "Small-signal modeling of the PWM boost DC-DC converter at boundaryconduction mode by circuit averaging technique," In proc. of IEEE symp. On circuit and systems ISCAS, 2015.
[9] S. A. Oliva, "Power-switching converters," Book CRC press, 2005.

[10] V. Michal, "Dynamic Duty-cycle Limitation of the Boost DC/DC Converter allowing Maximal Output Power Operations," In proc. of IEEE conf. Applied electronics, Pilsen, Czech Republic, 2016.

[11] D. Biolek, V. Biolkova, Z. Kolka, "Qveraged modeling of switched DC-DC converters based on Spice models of semiconductor switches," In proc. $7^{\text {th }}$ WSEAS int. conference CSECS'08, 2008

[12] "Understanding boost power stages in switchmode power supplies," Application report Texas Instrument SLVA061 1999, www.ti.com.

[13] J. B. Hoagg, D. S. Berstein, "Nonminimum-phase zeros much to do about nothing - clasical control revisited part II," IEEE control Systems, vol. 27, issue 3, pp. 45-57, 2007.

[14] V. Michal, "Modulated-ramp PWM generator for linear control of the boost converter's power stage," IEEE trans. on power electronics, vol. 27, No. 6, 2012.

[15] P. Arno, "DC/DC converter having a step-up converter supplying a step-down converter," US pat. US 20140333276, 2011.

[16] K. Viswanathan, R. Oruganti, D. Srinivasan, "A novel tri-state boost converter with fast dynamics," IEEE Trans. Powe. Electronics, vol. 18, No.5 2002

[17] R. Scheehan, "Understanding and applying current-moe control theory," PESC 2007, available at www.ti.com (ref. SNVA555, 2016).

[18] C. Qiao, J. Zhang, "Control of boost type converter in discontinuous conduction mode by controlling the product of inductor voltage-second,"in IEEE int. power electronics specialist conference 2005.

[19] B. Arbetter, D. Maksimovic, "Feed-forward pulse-width modulators for switching power converters," IEEE Power Electronics Specialist Conf. (PESQ), 1995.

[20] M.K. Kazimierczuk, A. Massarini, "Feedforward control of DC-DC PWM boost converter, IEEE Trans. Circuit and System I, Vol. 44, Issue 2, 1997.

[21] K. Egawa, "Regulator with pulse width modulation circuit", US patent US 20100194362, 2010.

[22] V. Michal, C. Premont, G. Pillonnet, N. Abouchi, "Single active element PID controllers," in Proceedings of $201020^{\text {th }}$ International Conference IEEE Radioelektronika, Brno, Czech Republic, 2010.

[23] V. Michal, C. Premont, G. Pillonnet, N. Abouchi, “Zeroderivative method of analog controller design applied to stepdown DC-DC converters," In proc. of IEEE Int. symposium on circuits and systems ISCAS 2010. 
